\title{
Изучение сортов и гибридов лука репчатого коллекции ВНИИГР в почвенно-климатических условиях Астраханской области
}

\author{
Studying of cultivars and hybrids of onion the VIR collections in soil climatic conditions of the \\ Astrakhan region
}

\author{
Середин Т.М., Шумилина В.В., Щербакова Н.А., \\ Селиверстова А.П., Баранова Е.В., Ушакова О.В., \\ Марчева М.М., Солдатенко А.В.
}

\section{Аннотация}

Цель исследований: изучение коллекционного питомника лука репчатого по основным хозяйственно ценным признакам в условиях Астраханской области. Исследования проводились в условиях вегетации 2017-2018 годов в Черноярском районе, на опытном участке Прикаспийского НИИ аридного земледелия, расположенном в северо-западной части Астраханской области. Почвы на участках изучаемой зоны - светло-каштановые, разной степени солонцеватости, занимают доминирующее положение в почвенном покрове рассматриваемой территории. В целом, погодные условия были неблагоприятными для выращивания лука репчатого. Опыты были заложены в соответствии с общепринятыми методиками согласно агротехнике лука репчатого в условиях Астраханской области. Для проведения исследований в 2017-2018 годах были использованы образцы из генетической коллекции ВНИИГР имени Н.И. Вавилова, а также образцы, отобранные в предыдущие годы. Коллекционный питомник лука репчатого был представлен 50 образцами, 26 из них выделились в годы исследований. Посев семян коллекционного питомника лука репчатого проводили в один срок: 3 мая (во все годы исследований). Получены результаты по выделившимся образцам коллекционного питомника лука репчатого по фенологическим фазам. Массовые всходы были отмечены на 12-22 сутки от посева. Фенологическая фаза «начало формирования луковиц» была отмечена на 61-68 сутки от посева. К раннеспелым образцам лука репчатого в коллекционном питомнике можно отнести: Сорокозубку, Suttons improved, Red mom, Nothern. Среднеспелыми образцами за годы изучения себя показали: Red Extra, Марковский, Vertus, Selfed, Jetset, Sillani Sargo. По основным хозяйственно ценным признакам выделились 15 коллекционных образцов. По выделившимся образцам лука репчатого средняя урожайность отмечена у пяти образцов: Maravanka, Алмадон, Southport, Selfed, Местный (Грузия), средняя масса товарной луковицы составила 151,6 г. По товарной урожайности выделилось три коллекционных образца: Zillani, Suttons improved, Encore. У сортообразца Марковский было отмечено 70\% товарных вызревших луковиц. Максимальная масса товарной луковицы 206,0 г была отмечена у коллекционного образца Cebola.

Ключевые слова: лук репчатый, сорт, гибрид, коллекционный питомник, почвенно-климатические условия.

Для цитирования: Изучение сортов и гибридов лука репчатого коллекции ВНИИГР в почвенно-климатических условиях Астраханской области / Т.М. Середин , В.В. Шумилина, Н.А. Щербакова, А.П. Селиверстова, Е.В. Баранова, О.В. Ушакова, М.М. Марчева, А.В. Солдатенко // Картофель и овощи. 2020. №2. С. 2830. https://doi.org/10.25630/PAV.2020.18.2.006

\author{
Seredin T.M., Shumilina V.V., Scherbakova N.A., Seliverstova \\ A.P., Baranova E.V., Ushakova O.V., Marcheva M.M., \\ Soldatenko A.V.
}

\section{Abstract}

The purpose of the present research was: to study the collection nursery of bulb onions on the main economic valuable features in the conditions of the Astrakhan region. The research was carried out in the conditions of the 2017-2018 vegetation in the Chernoyar district, on the experimental section of the Caspian research Institute of Arid agriculture, located in the north-western part of the Astrakhan region. Soils on the areas of the studied zone - light chestnut, different degree of salt content, occupy a dominant position in the soil cover of the considered territory. On the whole, weather conditions were unfavourable for the cultivation of bulb onions. The experiments were laid down in accordance with the generally accepted methodologies according to bulb onions agricultural machinery in the Astrakhan region. For research in 2017-2018 samples from the genetic collection VIR named after N.I. Vavilov were used, as well as samples taken in previous years. The collection nursery of bulb onions was represented by 50 samples, 26 of them stood out during the years of research. Sowing of seeds of collector nursery of bulb onions was carried out in one term: on May 3 (in all years of research). Results were obtained for selected samples of the collection nursery of onion by phenological phases. Mass shoots were observed on 1222 days from sowing. The phenological phase «the beginning of the formation of the follicles" was noted in 61 to 68 days from sowing. Early-maturing examples of onions in the collection nursery include: Sorokozubka, Suttons improved, Red mom, Northern. During the years of study, red Extra, Markovsky, Vertus, Selfed, Jetset, and Sillani Sargo showed themselves to be the middle-aged samples. According to the main economically valuable features, 15 collection samples were distinguished. According to the selected samples of onion, the average yield was noted in five samples: Maravanka, Almadon, Southport, Selfed, Local (Georgia), the average weight of the commodity bulb was $151.6 \mathrm{~g}$. According to the commodity yield, three collection samples were distinguished: Zillani, Suttons improved, Encore. In the Markovsky variety, $70 \%$ of commercially Mature bulbs were observed. The maximum mass of a commodity bulb of $206.0 \mathrm{~g}$ was noted in the collection sample of Cebola.

Key words: onion, grade, hybrid, collection nursery, soil climatic conditions

For citing: Studying of gradesand hybrids of onion the VIR collections in soil climatic conditions of the Astrakhan region. T.M. Seredin, V.V. Shumilina, A.P. Seliverstova, E.V. Baranova, O.V. Ushakova, M.M. Marcheva, A.V. Soldatenko. Potato and vegetables. 2020. No2. Pp. 2830 (In Russ.). https://doi.org/10.25630/PAV.2020.18.2.006 ультура лука репчатого была известна уже за четыре тысячи лет до н.э. [1]. В Государственный реестр селекционных достижений Российской Федерации на 2019 год внесено 195 сортов и 180 гибри- дов лука репчатого [2]. Цель исследований - изучение коллекционного питомника лука репчатого (Allium сера L.) по основным хозяйственно ценным признакам в условиях Астраханской области.

\section{Условия, материалы и методы исследования}

Исследования проводились в условиях вегетации 2017-2018 годов в Черноярском районе Астраханской области, на опытном участке 
Таблица 1 Фенологические наблюдения коллекционного питомника выделившихся образцов лука репчатого, 2017-2018 годы

\begin{tabular}{|c|c|c|c|c|c|}
\hline \multirow{2}{*}{ Образец } & \multicolumn{2}{|c|}{ Всходы, сутки } & \multirow{2}{*}{$\begin{array}{c}\text { Начало формиро- } \\
\text { вания луковиц от } \\
\text { посева (суток) }\end{array}$} & \multicolumn{2}{|c|}{$\begin{array}{c}\text { Полегание листьев, } \\
\text { суток от посева }\end{array}$} \\
\hline & начало & полные & & начало & полное \\
\hline $\begin{array}{l}\text { Марковский } \\
\text { (Украина) }\end{array}$ & 12 & 15 & 65 & 111 & 120 \\
\hline $\begin{array}{l}\text { Сорокозубка } \\
\text { (Россия) }\end{array}$ & 11 & 12 & 61 & 111 & 120 \\
\hline Red Extra (США) & 12 & 15 & 63 & 111 & 120 \\
\hline Кырмыз (Абхазия) & 19 & 22 & 68 & 111 & 120 \\
\hline $\begin{array}{l}\text { Suttons improved } \\
\text { (США) }\end{array}$ & 9 & 12 & 61 & 111 & 120 \\
\hline Maravanka (Чехия) & 19 & 22 & 68 & 111 & 120 \\
\hline Vertus (Дания) & 12 & 15 & 63 & 111 & 120 \\
\hline Каякентский (Россия) & 19 & 22 & 68 & 111 & 120 \\
\hline Алмадон (Россия) & 19 & 22 & 68 & 111 & 120 \\
\hline Southport (Канада) & 12 & 15 & 63 & 111 & 120 \\
\hline Selfed (Австралия) & 12 & 15 & 63 & 111 & 120 \\
\hline Местный (Грузия) & 12 & 15 & 63 & 111 & 120 \\
\hline Zillani (Венгрия) & 19 & 22 & 68 & 111 & 120 \\
\hline Jetset (Нидерланды) & 12 & 15 & 63 & 111 & 120 \\
\hline Encore (США) & 19 & 22 & 68 & 111 & 120 \\
\hline Cebola (Португалия) & 19 & 22 & 68 & 111 & 120 \\
\hline
\end{tabular}

Прикаспийского НИИ аридного земледелия, расположенном в северо-западной части области. Почвы на участках изучаемой зоны - светло-каштановые, разной степени солонцеватости, занимают доминирующее положение в почвенном покрове рассматриваемой территории. Реакция почвенного раствора - близкая к нейтральной (рН 7,2-7,6). Аридность климата оказывает влияние на темпы накопления и характер разложения органических остатков и определяет неблагоприятные условия процессов гумификации. Содержание гумуса в пахотном слое (0-25 cм) колеблется в пределах 0,95-
$1,2 \%$, легкогидролизуемого азота 6-9 мг, подвижного фосфора - 2-4 мг, обменного калия - 50-55 мг на 100 г почвы.

Для характеристики метеоусловий в 2017-2018 годах мы использовали данные агрометеостанции с. Черный Яр. Атмосферных осадков за вегетационный период выпало 107,4 мм, что на 32,4 мм меньше среднемноголетней нормы. Особенно аномальным по количеству осадков был май как 2017, так и 2018 годов - осадков не выпало (0,0 мм). Среднемесячная температура воздуха только в апреле была меньше среднемноголетнего значения. Май был теплее на $4^{\circ} \mathrm{C}$, а июнь на $1,5^{\circ} \mathrm{C}$, чем средние многолетние значения. Июль, август и сентябрь были жарче на 2,3; 0,5 и 2,3 ${ }^{\circ} \mathrm{C}$, соответственно, по сравнению со среднемноголетними показателями. Относительная влажность воздуха в апреле и июле была близка к средним многолетним показателям, за исключением мая, июня, августа и сентября, когда показатели влажности были ниже на 21, 20,9 и 9\%, чем среднемноголетние показатели. В целом погодные условия были неблагоприятными для выращивания лука репчатого.

Опыты были заложены в соответс-

Таблица 2. Основные хозяйственно ценные признаки коллекционного питомника (ВИР) лука репчатого, 2017-2018 годы

\begin{tabular}{|l|c|c|c|}
\hline \multicolumn{1}{|c|}{ Образец } & $\begin{array}{c}\text { Средняя масса } \\
\text { товарных } \\
\text { луковиц, Г }\end{array}$ & $\begin{array}{c}\text { Товарная } \\
\text { урожайность, т/га }\end{array}$ & $\begin{array}{c}\text { Биологическая } \\
\text { урожайность, Т/га }\end{array}$ \\
\hline Марковский (Украина) & 99,7 & 65,1 & 70,4 \\
\hline Cорокозубка (Россия) & 83,0 & 52,1 & 58,7 \\
\hline Red Extra (США) & 126,0 & 57,6 & 64,1 \\
\hline Кырмыз (Абхазия) & 111,2 & 35,2 & 50,2 \\
\hline Suttons improved (США) & 133,3 & 135,6 & 138,4 \\
\hline Maravankа (Чехия) & 148,2 & 29,4 & 30,4 \\
\hline Vertus (Дания) & 126,6 & 59,3 & 65,5 \\
\hline Kaякентский (Россия) & 130,2 & 55,6 & 62,9 \\
\hline Aлмадон (Россия) & 149,6 & 37,6 & 41,4 \\
\hline Southрогт (Канада) & 158,0 & 36,7 & 41,0 \\
\hline Selfed (Австралия) & 145,8 & 72,0 & 83,2 \\
\hline Mecтный (Грузия) & 156,2 & 76,0 & 89,8 \\
\hline Zillani (Венгрия) & 120,2 & 109,3 & 114,3 \\
\hline Jetset (Нидерланды) & 137,5 & 53,4 & 65,4 \\
\hline Encore (США) & 131,4 & 100,6 & 110,8 \\
\hline Cebola (Португалия) & 206,4 & 110,6 & 114,9 \\
\hline НСР & 1,8 & 5,1 & 2,1 \\
\hline
\end{tabular}

твии с общепринятыми методиками согласно агротехнике лука репчатого $[3,4,5]$. Посев опытных образцов производился вручную, 3 мая. Было посеяно 50 коллекционных образцов лука репчатого. Орошение опытного участка проводили с помощью системы капельного орошения. Хозяйственная годность у всех образцов наступала через 124 дня после всходов, уборку проводили через 134 дня.

\section{Результаты исследований}

Результаты по выделившимся образцам из коллекционного питомника представлены в табл. 1.

Коллекционный питомник лука репчатого был представлен 50 образцами, 26 из них выделились в годы исследований. Посев семян коллекционного питомника лука репчатого был произведен в один срок: 3 мая (во все годы исследований). Единичные всходы по образцам были отмечены на 9-19 сутки (12 мая и 22 мая соответственно). Единичные всходы у четырех коллекционных образцов лука репчатого 12 мая были отмечены: Сорокозубка, Suttons improved, Red Extra, Vertus. Macсовые всходы были отмечены на 12-22 сутки от посева. Фенологическая фаза «начало формирования луковиц» была отмечена на 61-68 сутки от посева. К раннеспелым образцам лука 


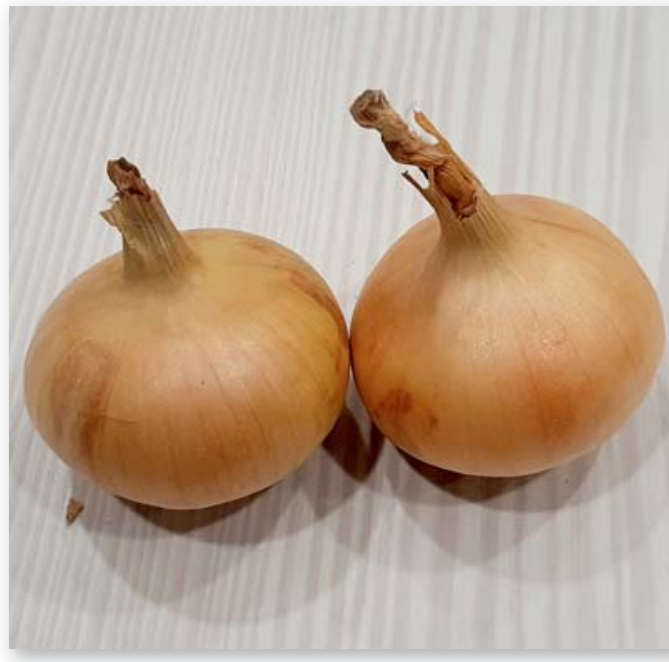

Образец Zillani

репчатого в коллекционном питомнике можно отнести: Сорокозубку, Suttons improved, Red mom, Nothern. Среднеспелыми образцами за годы изучения себя показали: Red Extra,
Марковский, Vertus, Selfed, Jetset, Sillani Sargo.

В условиях 2017-2018 годов при полном количественном анализе была также изучена изменчивость наиболее важного параметра для характеристики изучаемых образцов лука репчатого, как масса луковицы (табл. 2).

По признаку «масса товарной луковицы» наибольшие межсортовые отличия получены между образцами Сорокозубка и Cebola. По остальным образцам необходимо отметить, что средняя урожайность отмечена у пяти образцов: Maravanka, Алмадон, Southport, Selfed, Местный (Грузия), средняя масса товарной луковицы составила 151,6 г. При этом у образца Марковский масса луковицы в среднем за два года исследований составила 99,7 г. Максимальная масса товарной луковицы была отмечена у коллекционного образца Cebola (206,4 г). Генетическая составляющая межсор- товой изменчивости (Cvg) по признаку «масса товарной луковицы» была средней и составила в разные годы исследований $20,5 \%$.

Высокая степень варьирования вызревших товарных луковиц изученных образцов в зависимости от агроэкологических условий выращивания обуславливает и высокую изменчивость признака «урожайность» у большинства сортов и коллекционных образцов. Так, у сортообразца Марковский было отмечено $70 \%$ товарных вызревших луковиц.

\section{Выводы}

Таким образом, по товарной урожайности выделилось три коллекционных образца: Zillani, Suttons improved, Encore. У сортообразца Марковский было отмечено 70\% товарных вызревших луковиц. Максимальная масса товарной луковицы 206,0 г была отмечена у коллекционного образца из Португалии - Cebola.

\section{Библиографический список}

\section{References}

1.Черемушкина В.А. Биология луков Евразии. Новосибирск, 1988. 184 c.

2.Государственный реестр селекционных достижений, допущенных к использованию. Т. 1: Сорта растений [Электронный pecypc]. URL: http//reestr.gossort.com/reestr. Дата обращения: 31.10.2019.

3.Методические указания по изучению и поддержанию в живом виде мировой коллекции лука и чеснока. Санкт-Петербург, 2005. С. 20-36.

4.Методические указания по экологическому испытанию овощных культур в открытом грунте. Ч. 2. М., 1985. 30 с.

5.Ершов И.И. и др. Методические указания по селекции луковых культур. М., 1997. 118 с.
1. Cheremushkina V.A. Biology of Eurasian bows. Novosibirsk, 1988. 184 p. (In Russ.).

2. State register of selection achievements approved for use. Vol. 1: plant Varieties [Web resource]. URL: http//reestr.gossort.com/ reestr. Date of access: 31.10.2019. (In Russ.).

3.Guidelines for studying and keeping alive the world's collection of onions and garlic. Saint-Petersburg, 2005. Pp. 20-36 (In Russ.).

4.Guidelines for environmental testing of vegetable crops in the open ground. Part 2. M., 1985. 30 p. (In Russ.).

5.Ershov I.I. et al. Guidelines for the selection of onion crops. M. 1997. 118 p. (In Russ.).

\section{Об авторах}

Середин Т.М. (ответственный за переписку), канд. с.-х. наук, с.н.с. лаборатории селекции и семеноводства луковых культур, ФГБНУ Федеральный научный центр овощеводства. E-mail: timofey-seredin@rambler.ru

Шумилина В.В., канд. С.-х. наук, н.с. отдела овощных культур отдела овощных культур, ФГБНУ ФИЦ Всероссийский институт генетических ресурсов им. Н.И. Вавилова

Щербакова Н.А., канд. с.-х. наук, с.н.с., ФГБНУ Прикаспийский аграрный федеральный научный центр Российской академии наук

Селиверстова А.П., м.н.С., ФГБНУ Прикаспийский аграрный федеральный научный центр Российской академии наук

Баранова Е.В., канд. с.-х. наук, н.С. лаборатории селекции и семеноводства луковых культур, ФГБНУ Федеральный научный центр овощеводства

Ушакова О.В., канд. С.-х. наук, С.н.с. лабораторно-аналитического центра, ФГБНУ Федеральный научный центр овощеводства

Марчева М.М., М.н.с. лаборатории селекции и семеноводства луковых культур, ФГБНУ Федеральный научный центр овощеводства

Солдатенко А.В., доктор с.-х. наук, гл.н.с. лабораторно-аналитического центра, директор ФГБНУ Федеральный научный центр овощеводства

\section{Author details}

Seredin T.M., (correspondence author), Cand. Sci. (Agr.), senior research fellow of laboratory,s associative of selection and seed farming onions cultures, Federal State Budgetary Scientific Institution Federal Scientific Center of Vegetable Growing (FSBSI FSCVG). E-mail: timofey-seredin@rambler.ru

Shumilina V.V., Cand. Sci. (Agr.), senior research fellow of department of vegetable cultures, Federal Research Center N. I. Vavilov All-Russian Institute of Plant Genetic Resources (VIR)

Scherbakova N.A., Cand. Sci. (Agr.), senior research fellow, FSBSI Caspian agricultural Federal scientific center of the Russian Academy of Sciences (FSBSI CAFSC RAS)

Seliverstova A.P., junior research fellow, FSBSI CAFSC RAS

Baranova E.V., Cand. Sci. (Agr.), senior research fellow associative of laboratory, s associative of selection and seed farming onions cultures, FSBSI FSCVG

Ushakova O.V., Cand. Sci. (Agr.), senior research fellow analytical center, FSBSI FSCVG

Marcheva M.M., junior research of laboratory,s associative of selection and seed farming onions cultures, FSBSI FSCVG

Soldatenko A.V., D. Sci. (Agr.), chief research fellow of analytical center, director, FSBSI FSCVG 